\title{
History and Strategies of Drug Information Services at Ministry of Health in Saudi Arabia
}

\begin{abstract}
Yousef Ahmed Alomi*, (iD The Former General Manager of General Administration of Pharmaceutical Care Former Head, National Clinical Pharmacy and Pharmacy Practice Former Head, Pharmacy R and D Administration Ministry of Health, Riyadh, SAUDI ARABIA.

Saeed Jamaan Alghamdi, General

Administration of Pharmaceutical Care, Ministry of Health, Riyadh, SAUDI ARABIA. Radi Abdullah Alattyh, General Administration of Pharmaceutical Care, Ministry of Health, Riyadh, SAUDI ARABIA.
\end{abstract}

\section{Correspondence: \\ Dr. Yousef Ahmed Alomi, \\ The Former General Manager of General Administration of Pharmaceutical Care, The Former Head, National Clinical Phar- macy and Pharmacy Practice, The Former Head, Pharmacy R and D Administration, Ministry of Health, Riyadh, SAUDI ARABIA.}

Phone no: +966504417712

E-mail: yalomi@gmail.com
Received: 11-11-2018;

Accepted: 15-12-2018

Copyright: (c) the author(s),publisher and licensee Pharmacology, Toxicology and Biomedical Reports. This is an open-access article distributed under the terms of the Creative Commons Attribution NonCommercial License, which permits unrestricted non-commercial use, distribution, and reproduction in any medium, provided the original work is properly cited.

This is an open access article distributed under the terms of the Creative Commons Attribution-NonCommercial-ShareAlike 4.0 License

Access this article online

\begin{tabular}{|l|l|}
\hline & www.ptbreports.org \\
& DOI: \\
\hline & \\
&
\end{tabular}

\section{ABSTRACT}

Over more thirty years back the first drug information services founded at Ministry of Health institutions in the Kingdom of Saudi Arabia. The drug information services stated with very simple and essential to the comprehensive with high quality and quantity specialized pharmacy practice. The services transferred over several periods from established time to advance stage and public stage. The drug information strategic plan founded for five years and included the updated Pharmacy strategic plan with Saudi vision 2030. The new drug information services started for the public with hotline at the Ministry of Health in the Kingdom of Saudi Arabia.

Key words: History, Strategies, Drug Information, Services, Ministry of Health, Saudi Arabia.

\section{Historical overview}

\section{9-1998}

In 1989, the first drug and poison information center was founded at Riyadh Central Hospital as part of the clinical pharmacy services; it is headed by a regular pharmacist and is supervised by the Saudi clinical pharmacist, who holds a Master of Clinical Pharmacy degree from the University of Pacific California State USA. The center provides answers to the questions, gives educational lectures to the healthcare professionals and publishes newsletter on pharmacy which is disturbed monthly across all $\mathrm{MOH}$ hospitals. It works $8 \mathrm{hrs}$ per day and does not provide services during evenings, night, or weekends. It is well-equipped with manual references (i.e., books on drug information such as Martindale, Remington, British National Formulary, Microfiche and Micromedex Drugdex) with manual documentation of drug information inquiries. ${ }^{1}$ In 1994, the staff members increased from two to three pharmacists and the number of questions and books was also increased and updated. Micromedex became computerized and the hospital's PTC started monitoring the adverse drug reactions and medication errors and conducted programs on drug quality reporting systems. The center was engaged and participated in publishing the third $\mathrm{MOH}$ formulary in 1989 and the fourth formulary in 1997. It was involved in the preparation of exams for pharmacists working at $\mathrm{MOH}$ to obtain license before the founding of the Saudi Commission of Health Specialties. The center evaluates new medications for registration in Saudi Arabia through Administration of Medical and Medication licensing. ${ }^{1}$

\section{8-2008}

During this period, there were minor changes along with the continuation of previous activities and updating of the system (e.g. electronic drug information inquiries, adverse drug reaction and medication errors) along with the expansion of number of hospitals providing services from one to three hospitals and then to King Saud Medical City hospital with more than 1500 beds. It increased drug information resources with Internet access and some online database. The center started to train students in Bachelor of Science in Pharmacy as an internship. The center started participating in platform and poster presentations at local pharmacy conferences; it presented two lectures at the 5th Saudi Pharmaceutical Society Conference in 1999 and several lectures in several conferences inside Saudi Arabia and outside the KSA. ${ }^{1}$

\section{8-2012}

During this period, tremendous changes and expansions in services took place. The CEO of King Saud Medical City changed from being a local center to a Regional Drug and Poison Information Center via Circular No 29/1/2286, 28-9-1422 (13-12-2001) cover all areas in Riyadh city in their services including their hospitals. It was headed by the clinical pharmacist who was holding a degree in Master of Science in clinical pharmacy and the certificate from Board of Pharmacotherapy Specialties along with 10 years of experience as a critical care clinical pharmacist. The drug information center staff expanded from 2 to 10 clinical pharmacists covering $8 \mathrm{hrs}$ during the morning and 16 hrs on call drug information clinical pharmacist. The center was founded based on ASHP guidelines. Drug information and poison services, medication safety, drug utilization evaluation, pharmacoeconomic, pain management, anticoagulation and antibiotic stewardship programs were all running and followed-up with workload documentation system of clinical pharmacist and nonpharmacists together with pharmacist intervention. Job description with policies and procedures for the aforementioned programs were prepared and approved by the hospital's Total Quality Management (TQM) director, Assistant CEO of Medical Affairs and finally by the CEO. Newsletters 
were reactivated again on August 2011. Drug information program was started with the offering of internship training for Diploma in Pharmacy students, upgraded the documentation drug information inquiries by using United Kingdom (UK) system by name MiDatabank medication information system and participated as a member of corporate $\mathrm{MOH}$ PTC. It started publishing poster abstract through international conference American College of Clinical Pharmacy (ACCP) with a new model of drug and information center in 2009. ${ }^{1,2}$

\section{2-2022}

The new vision of drug information services was started during this period. The Regional Center of Drug and Poison Center was transferred to the GAPC and its roles were expanded to cover all MOH hospitals and PCCs including public services. The name was changed to NDIC and includes all previous programs expanded to cover $\mathrm{MOH}$ hospitals based on the strategic planning of the GAPC approved by the Minister of Health. A central committee was established in 2012 with representative members from all 20 regions and a network of regional committees of drug information centers were founded at areas. NDIC activated e-communication newsletters on therapeutic updates and medication safety, which was sent on a monthly basis to all the registered healthcare professionals via Phacare-NCDI@moh.gov.sa. NDIC participated with Saudi center for EBHC in 2014 and to publish clinical practice guidelines. All drug information forms were upgraded to an electronic format online base to ease the documentation process, i.e., drug information inquires (hospital base or 937 call center) and self-assessment of drug information center, which is based on the GAPC website. On December 2013, NDIC started providing 937 hotline services with 11 clinical and trained pharmacists who ran the facility 24/7; this service has expanded now to cover the whole of KSA with 48 clinical and trained pharmacists across 12 regions in $2014 .^{1,3,4}$

\section{Strategic Plan of Drug Information Services}

GAPC has set a 5-year plan (stages 1-5) for drug information program throughout the KSA: In stage I (2014), there was establishment of central drug information committee; drug information centers (90) in 20 peripheral hospitals across various regions of the KSA; and publishing drug information manual and electronic booklet. Furthermore, there were drug information training courses and there was establishment and running of a $24 / 7$ call center at the national drug information center at 20 regions across the KSA.

In stage II (2015), there was establishment of additional 90 drug information centers at peripheral hospitals; establishment of drug information center at PHCs across 20 regions; and there was documentation of central drug information inquires across 20 regions and 90 hospitals of Stage I. Furthermore, there was sharing of drug information across 20 regional PTCs and in 90 hospitals and PCCs and conducting of one complete drug evaluation in the regional PTCs and in 90 hospitals and PCCs. Moreover, follow one guidelines in the area and in 90 hospitals and PCC, drug information training courses central and in 20 regions and continuity of the call center and its cost avoidance.

In stage III (2016), there was expansion of drug information centers by 70 more centers in peripheral hospitals and a total of 40 PCC, with the documentation central, 20 region and 180 hospital with the 20 PCC of stage II, drug information training courses central and in 20 regions and continuity of the call center. Drug information sharing in 20 regional PTCs and PCCs and private hospital in 180 hospitals, PCC and private hospitals with at least one drug evaluation.

In stage IV (2017), there was expansion of drug information centers by 90 private hospitals and 60 PCCs, documentation of drug information inquires of previous stage, 20 regions (250 hospitals with the PCC) of stage III, drug information training courses central and in 20 regions and continuity of the call center. Drug information sharing in 20 regional PTCs and PCC and private hospital in 180 hospitals, PCC and private hospital with at least one drug evaluation in 250 hospitals and PCC and private hospital and training courses in both $\mathrm{MOH}$ and private Hospitals.

In stage V (2018); drug information centers peripheral additional 90 private hospital and 80 region PCC, documentation of drug information inquires of previous stage, 20 region (250 hospital with the PCC) and private hospitals of Stage IV. Drug information training courses central and in 20 regions and continuity of the call center. Drug information sharing in 20 regional PTCs and PCC and private hospital in 250 hospitals, PCC and private hospital and following one guideline in region and the continuity of training courses in both $\mathrm{MOH}$ and private hospitals. During 2022-2032, the plan will be revised and updated of strategic plan of drug information services every 10 years until 2042..$^{1,3,5}$

\section{Cost avoidance of drug information}

ASHP publishes regarding the drug information services and roles of the pharmacist. ${ }^{2}$ Several investigations conducted in the KSA and across of the world show the impact and cost avoidance of drug information services. ${ }^{4,6-8}$ Most of the cost avoidance was related to the impact of answering question. The other related cost avoidance of impact drug information services need to be measured. For instance, drug evaluation activities, public health education, PTC activities, training of pharmacy students and residents. All those spaces are the area for researches in the future.

\section{Cost analysis of drug information}

There are a few studies conducted in the KSA and in rest of the world about cost analysis of drug information services. Two studies conducted in the KSA addressed the basic foundations of drug information services at normal and mental hospitals. ${ }^{9,10}$ Other studies have discussed the cost of drug information activities including education and training. ${ }^{11}$ The cost analysis information is a starting point to measure the economic impact of drug information services rather than answering questions.

\section{Do we need drug information centers or services?}

If we analyze the cost of drug information services and cost avoidance, the results will guide the healthcare institute which needs to pay a significant amount of money to establish a drug information center. The pharmacist should provide excellent and vital services related to the cost avoidance. The healthcare administration should weigh between creating formal drug information center with a full-time employee or provide informal drug information services. All drug information service distribution among the working pharmacist as part of their job. For instance, all working pharmacists answer drug information inquiries with complete documentation; if any new drug is required to be added in the hospital's drug formulary, then the clinical pharmacist can handle it based on the medication specialties. For instance, if a new drug for cardiovascular disease needs to be included in the drug formulary, then cardiology clinical pharmacist can evaluate the drug for inclusion. Moreover, pharmacy students or resident pharmacy students can distribute drug information activities among pharmacy preceptors and the PTC can be included as part of the drug evaluation process for each pharmacist. As a result, the cost of foundation will diminish and increase the cost of avoidance of each drug information service. ${ }^{1,2}$

\section{New Saudi Vision 2030 of drug information}

The drug information services should implement the updated pharmacy strategic plan at MOH with New Saudi Vision 2030 including cost of all previous services and foundations and impact of economic avoidance. Moreover, the pharmacist provided services through 937 should 
be part of the drug information services for the public and professionals. The first call was answered by a pharmacist working at 937 and any further inquiries should be forwarded to the expert drug information pharmacist. All drug information activities should be performed by the healthcare team and $\mathrm{MOH}$ should follow-up the implementation of the services according to the national and international guidelines and international standards within the KSA. ${ }^{12,13}$

\section{CONCLUSION}

The history of drug information services in Saudi Arabia developed over several years from primary to high advance service. Expanding services to the public is fitting of new Saudi vision 2030. The drug information services demandable to key performance indicators to follow up with the clinical and economic outcomes of the services in the Kingdom of Saudi Arabia.

\section{ACKNOWLEDGEMENT}

I want to thank all inventory management and medical supply pharmacists at all regions for their cooperation.

\section{CONFLICT OF INTEREST}

The authors declare no conflict of interest.

\section{ABBREVIATIONS}

ASHP: American Society of Health-System Pharmacist; EBHC: evidence-based healthcare; CEO: Chief Executive Officer; KSA: Kingdom of Saudi Arabia; MOH: Ministry of Health; NDIC: National drug information center; ACCP: American College of Clinical Pharmacy; TQM: Total Quality Management; PCCs: Primary care centers; PTC: Pharmacy and Therapeutic Committee; RPCA: Regional Pharmaceutical Care Administration; GAPC: General Pharmaceutical Care Administration.

\section{ORCID ID}

Yousef Ahmed Alomi (D) https://orcid.org/0000-0003-1381-628X

\section{REFERENCES}

1. YA A. National Drug Information Center Program at Ministry of Health in Saudi Arabia. Adv Pharmacoepidemiol Drug Saf. 2016;5(1):1-2.

2. Ghaibi S, Ipema HGM. ASHP Guideline on The Pharmacist's Role in Providing Drug Information. Am J Heal Pharm. 2015;72(7):573-7.

3. Alomi YA, Alghamdi SJ, Alattyh RA. Strategic Plan of General Administration of Pharmaceutical Care at Ministry of Health in Saudi Arabia 2012 - 2022. J Pharm Pharm Scien. 2015;1(13):1-8

4. Alomi YA, Almudaiheem HY, Alarnous T, Alshurei S, Alsharafa A, Alzahrani T, et al. Cost-Efficiency of of National Drug Information Center Through Ministry of Healh Hotline Calling Services (937) in Saudi Arabia: Application of a Mercian Model. Value Heal. 2015;18(7):A735

5. Alomi Y. National Pharmacy Administration Programs. BAOJ Pharm Sci. 2015;1(2):1-2

6. Alomi YA Cost-Efficiency Of Clinical Pharmacy Services At Ministry Of Health In Saudi Arabia Application Of American Model. Value Heal. 2016;19(7):A482-3.

7. Kinky DE, Erush SC, Laskin MS, Gibson GA. Economic Impact of a Drug Information Service. Ann Pharmacother. 1999;33(1):11-6.

8. Bond CA, Raehl CL, Franke T. Clinical Pharmacy Services, Pharmacist Staffing and Drug Costs in United States Hospitals. Pharmacotherapy. 1999;19(12):135462.

9. Alomi YA, Alsulami N, Qahtani NAl, Mashouf M, Qahtani A, Almansor FA. Cost Analysis of Drug Information Services at the Mental Hospital in Saudi Arabia. Journal of Pharmacy Practice and Community Medicine. 2018;4(2):83-6.

10. Alomi YA, Al-Jarallah SM. The Cost Analysis of Network Drug Information Services at Ministry of Health Institutions in Saudi Arabia. J Pharm Pract Community Med. 2018;4(4):226-30.

11. Alomi YA, Bahdailah AA, Alohaly AK. National Analysis of Network Drug Information Centers: Education, Training and Related Cost at Ministry of Health Hospitals in Saudi Arabia. J Pharm Pract Community Med. 2018;4(4):231-6.

12. Alomi YA. New Pharmacy Model for Vision 2030 in Saudi Arabia. J Pharm Pract Community Med. 2017;3(3).

13. Alomi YA, Alghamdi SJ, Alattyh RA, Elshenawy RA. The Evaluation of Pharmacy Strategic Plan in Past 2013-2016 and Forecasting of New Vision 2030 at Ministry of Health in Saudi Arabia. J Pharm Pract Community Med. 2018;4(2):93-101. 